\title{
CHEMOTHERAPY OF CANCER
}

\author{
By K. A. NewTon, M.R.C.P., F.F.R. \\ Consultant Radiotherapist, Westminster Hospital
}

\section{Introduction}

The Seventh International Cancer Congress, recently held in London, has underlined the research that is being carried out on a world-wide basis, aimed at the discovery of chemical agents of value in the treatment of cancer. Undoubtedly a major part of this effort has fallen to the United States of America where, in a single year, over 40,000 compounds have been investigated for antitumour activity. In the Soviet Union there is an active and progressive school of chemotherapy and this country has also made a valuable contribution, particularly in the field of alkylating agents of chemotherapeutic value.

Modern cancer chemotherapy can be said to have started during and shortly after the Second World War when the first clinical trials of nitrogen mustard were conducted in the United States (Rhoads, ${ }^{1}$ Goodman et al. ${ }^{2}$; and in this country by Wilkinson $^{3}$ ). Since then in the relatively short period of 15 years, a very large number of compounds have reached the stage of clinical trial and there are approximately 20 which now have an accepted place in the treatment of various types of neoplastic disease. Following the discovery of nitrogen mustard $\left(\mathrm{HN}_{2}\right)$, a further massive step forward was made in the chemical treatment of cancer by the discovery of aminopterin in - 1948, by Dr. Farber ${ }^{4}$ and his group in Boston. This anti-metabolic substance is capable of causing prolonged remission in acute leukaemia. These two compounds, then, represent the two great classes of chemotherapeutic agents. Nitrogen mustard is an example of an alkylating agent and aminopterin of an anti-metabolite.

The potentialities of nitrogen mustard have led workers to search for other forms of chemically active alkylating agents, and this has resulted in the discovery of the ethylenimines of which TEM was the first compound commonly used in clinical practice. : The suphonyl oxybutanes of which the anti-leukaemic substance, myleran, is a wellknown example, furnishes further proof of the search for new alkylating agents. In the United States much work has been done on the antimetabolites and many new examples of these compounds have now reached the stage of clinical trial and some, such as 6-mercaptopurine, a potent anti-purine, have an accepted place in clinical medicine.

Classification
Alkylating Agents
I. Mustards:
$\mathbf{H N}_{2}$ and $\mathrm{HN}_{3}$
$\mathrm{CB}_{1048}$ (erysan)
Nitromin
CB $\mathbf{3}^{3} 8$ (leukeran and chlorambucil)
CB 3025 (melphalan and sarcolysin)
Degranol (BCM)
Hemi-sulfur mustards
Chloroquine and quinacrine mustards
2. Ethylenimines:
TEM
ThioTEPA
E 39 (ethylenimino quinone)
3. Suphonyl oxybutanes:
Myleran (busulphan)
Dimethyl myleran
Nonane
4. Epoxides:
Di-epoxybutane

Anti-metabolites

I. Folic acid antagonists:

Aminopterin

Amethopterin

Dihydrotriazines

2. Glutamine antagonists:

Azaserine

3. Purine antagonists:

6-Mercaptopurine (purinethol)

Puromycin

6-Chloropurine

4. Pyrimidine antagonists:

2-Thiouracil

5. Amino acid antagonists:

Ethionine

Selenium cystine

Hydroxylysine

6. Probable anti-metabolites:

Actinomycin C 
Actinomycin D

\section{Urethane}

\section{General Cell Poisons:}

\section{Colcemid (demecolcin) Thiocolciran}

This classification, though containing the names of a large variety of compounds, cannot be considered to be fully comprehensive. Those compounds (in heavy type) can be said to have passed through the stage of full experimental and clinical trial and to have an established place in the treatment of advanced neoplasia.

An account will now be given of the more important compounds, omitting many chemical agents, which though active, possess no particular advantage.

\section{ALKYLATING AGENTS}

\section{Nitrogen Mustard}

During the last war a clinical trial was conducted both in this country and in America, into compounds which have since become known as $\mathrm{HN}_{2}$ and $\mathrm{HN}_{3}$ (Rhoads, ${ }^{1}$ Goodman et al. ${ }^{2}$ and Wilkinson $^{3}$ ). These substances are derivatives of the First World War mustard gas, and since their description, $\mathrm{HN}_{2}$ in particular has been used very extensively in the treatment of lymphomas, leukaemias and advanced tumours. $\mathrm{HN}_{2}$ (Methylbis ( $\beta$-chloroethyl)amine hydrochloride) is capable of producing dramatic and prolonged remission in Hodgkin's disease and other lymphomas. It can bring about complete disappearance of large gland masses; restoration of a high pyrexia to normal, diminution in size of spleen and return of the patient to good health. It is also useful in chronic lymphatic leukaemia, where the condition has passed to one of progressive lymphadenopathy and hepato-splenomegaly associated : with anaemia. This type of case does not, as a rule, respond completely, and is liable to undue haematological depression. Occasionally $\mathrm{HN}_{2}$ is capable of producing temporary objective improvement in disseminated epithelial cancer, but the frequency with which this occurs scarcely makes this treatment worth while as a routine method. As it is given intravenously and has a variety of sideeffects, it is more suitable for in-patient administration and short course therapy.

Side-effects. Nausea, vomiting, pyrexia, white cell count depression particularly lymphopaenia, depression of haemoglobin and platelets.

Dose. Usual dosage is 0.1 to $0: 4 \mathrm{mg}$. per $\mathrm{kg}$. daily' for four to five injections. The author prefers to give a routine graduated dose increase starting: at $2 \mathrm{mg}$. and working up to $8 \mathrm{mg}$. per injection on alternate days, being guided by the individual variation in toxic and haematological effects.

\section{Leukeran (Chlorambucil)}

Leukeran (CB 1348) (p-(di-2-chloroethylamino)-phenylbutyric acid) was first synthesized in this country at the Chester Beatty Research Institute by Everett $e t a l . .^{5}$ and is an example of the development by bio-chemists of the original $\mathrm{HN}_{2}$ formula. This compound is an aromatic substance as opposed to the aliphatic $\mathrm{HN}_{2}$, is nonvesicant and can be taken by mouth. In the past few years it has become well established that leukeran has a definite part to play, particularly in the malignant lymphomas. Altman et al. ${ }^{6}$ describe II out of 18 cases of chronic lymphatic leukaemia which had objective improvement rated from good to excellent. Galton et al. ${ }^{7}$ in treating six cases of giant follicular lymphoma had five which experienced ' good benefit,' when only four of 23 with Hodgkin's disease had a similar good response, although in 14 cases there was some effect, and no observable effect in five cases. Results in reticulum cell sarcoma have been disappointing, as have many of the other cytotoxic agents. Leukeran has the great advantage that it can be used for out-patient therapy, is quite capable of controlling and temporarily arresting disease progress in lymphomas and the effective therapeutic dose level can be considered safe. Pillers and Magalini ${ }^{8}$ have stated that there is no observable haematological effect in a dosage of ? $0.15 \mathrm{mg}$. per kg. per day. This is borne out by the experience at Westminster Hospital where it is found possible to give a daily dosage of $5 \mathrm{mg}$. for six months with no observable effect on the white or red cell count.

Side-effects. Very occasional mild nausea and anorexia. Haemopoietic depression after prolonged treatment with large doses.

\section{Melphalan (CB 3025) (Sarcolysin)}

This substance P-Di-2-Chloroethylamino-LPhenylalanine synthesized simultaneously both in this country at the Chester Beatty Research Institute and in the Soviet Union, has been reported on very favourably, particularly in the U.S.S.R. (Larionov et al.,9 Blokhin et al. ${ }^{10}$ ). It has been postulated that the amino acid phenyl analine grouping acts as a carrier for the transport of the mustard to the site of action (Larionov et al. ${ }^{9}$ ). They consider that this compound is very much more efficacious against solid tumours than other previously described nitrogen mustard derivatives. Amongst the more significant results claimed, have been the production of tumour regression in 19 out of 23 cases of seminoma of the testis, and three out of six cases of multiple 
myeloma. ${ }^{10}$ Other solid tumours in which success has been claimed are angio-endotheliomas, Ewing's tumours and apart from these, reticulosarcomas. There has been little experience of its use in this country, but Papac et al. ${ }^{11}$ describe 37 cases, one of which, a teratoma of the testis, derived considerable benefit following $250 \mathrm{mg}$. given in three months. In the United States, Holland and Regelson $^{12}$ describe the use of melphalan in 16 patients with malignant melanoma of which only two showed a limited objective improvement.

Dosage. $10 \mathrm{mg}$. daily for two to three weeks, or alternatively, 4 to $6 \mathrm{mg}$. daily for eight to ten weeks. At more than $20 \mathrm{mg}$. daily some nausea and vomiting are evident. Neutropenia and thrombocytopenia may occur after two to three weeks at a dose of $10 \mathrm{mg}$. daily. Whilst this substance must be considered an extremely interesting one and a probable precursor of other similar amino acid mustards, its precise position in the treatment of advanced malignancy is unknown. It seems that its use is justified in the radio-sensitive type of disseminated solid tumours.

\section{Degranol (BCM)}

In Hungary, this compound $(\mathrm{I}, 6-\mathrm{Bis}(\beta$-chloroethylamino)-1, 6-Deoxy-D-Mannitol Dihydrochloride) has been extensively used in a large number of patients; for example, 318 were reported by Sellei and Eckhardt. ${ }^{13}$ It is claimed that this substance is more efficacious and less toxic than $\mathrm{HN}_{2}$, for although sickness, malaise and vomiting do occur, these reactions are not severe and occur in approximately 45 per cent. of cases. These side-effects are most evident when the dose level is more than $0.3 \mathrm{mg}$. per $\mathrm{kg}$. Isolated successes are claimed in various miscellaneous solid tumours. Their most striking success was 22 cases out of 59 cases of Hodgkin's disease which were stated to have remained symptomless for two years following a course of treatment. This substance has recently become available in this country and it would seem worth while giving it a trial particularly in cases where intravenous therapy is advised and as an alternative to intravenous nitrogen mustard.

Dosage. $50 \mathrm{mg}$. alternate days up to 600 or $800 \mathrm{mg}$.

Side effects. Nausea, anorexia, vomiting and bone marrow depression.

\section{TEM}

Rose et al..$^{14}$ investigated the inhibitory action of various ethyleneimine compounds against animal tumours and found that TEM (triethylenemelamine) was the most effective of the compounds tested. Subsequently this compound was tested clinically by Bayrd et al. ${ }^{15}$ in $3^{8}$ patients, the most striking results being obtained in chronic lym- $\frac{0}{0}$ phatic leukaemia. Improvement was observed in ڤ 8 out of 13 cases treated. Rundles and Barton ${ }^{16} 3$ considered that TEM was the agent of choice in $\stackrel{\mathbb{2}}{\complement}$ the treatment of chronic lymphatic leukaemia, $\subset$ although a 30 per cent. remission was obtained $\overrightarrow{\vec{F}}$ in Hodgkin's disease (Silverberg and Damashek ${ }^{17}$ ). $\frac{\text { ? }}{0}$ It is now recognized that although this drug is capable of producing good tumour regression and $\frac{\bar{\sigma}}{\bar{D}}$. symptomatic improvement in lymphomas it is $\vec{\nabla}$ liable to cause extensive bone marrow damage $\varrho$ particularly in lymphatic leukaemia. This bone की marrow damage does not manifest itself till some- $\vec{\circ}$ times one to three weeks after the completion of $\overrightarrow{ }$ treatment. Kravitz et al. ${ }^{18}$ have described kidney $\vec{\omega}$ damage and haematuria, polyuria and uraemia $\frac{\Omega}{\circ}$ and Bayrd et al. ${ }^{15}$ describe renal failure in their $\frac{C}{\exists}$ patients who died whilst on TEM therapy.

Dose. It is preferred to give TEM at not more than $2 \frac{1}{2} \mathrm{mg}$. on alternate days and it is possible to give 15 to $30 \mathrm{mg}$. total.

\section{Side effects}

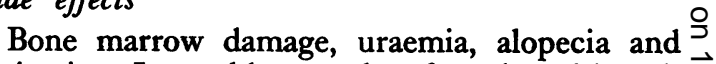
urticaria. It would seem therefore that although $\vec{\nabla}$ this agent is effective in lymphomas chronic $\mathbb{\complement}_{\mathbb{\infty}}^{\mathbb{D}}$ myeloid and chronic lymphatic leukaemias it is $\frac{\Phi}{3}$ perhaps more toxic than other equally efficacious compounds. If it is used it should be under clos haematological supervision.

\section{ThioTEPA}

ThioTEPA Triethylenethiophosphoramide is a development of TEM to which it is related chemically and has been studied extensively clinically, particularly in the United States. It is $\stackrel{\circ}{\mathbb{Q}}$ a substance which has been subjected to widely $\stackrel{2}{\vec{F}}$ differing reports, for example, Bateman, $\mathbf{M c C a b e}{ }^{19}$ 응 reported that 25 out of 32 patients with advanced $\frac{3}{5}$ carcinoma of the breast were significantly palliated and six of 12 with ovarian carcinoma also had good results, whereas Ultmann et al..$^{20}$ describe uniform $\frac{}{3}$ failure in response in breast carcinomas. There is no doubt that Thio'TEPA is capable of pro- 3 . ducing a good remission in the lymphoma group of patients, for example, Ultmann et al. ${ }^{20}$ describe $₹$ 19 of 43 patients with malignant lumphomas who 0 showed definite objective improvement. Our experience at Westminster Hospital of intravenous ThioTEPA shows that it appears to possess no therapeutic advantage over intravenous $\mathrm{HN}_{2}$. N Ultmann et al. describe haematological toxicity $N$ with depression of white cell count in 45 per cent. N of patients having reasonable doses of ThioTEPA. No other toxic effects are mentioned with any frequency.

Dose. Average $50 \mathrm{mg}$. total intravenousty over $\stackrel{\overparen{D}}{\rightarrow}$ seven days. 


\section{Myleran (Busulphan)}

In r953, Haddow and Timmis ${ }^{21}$ described the synthesis of 1 :4-dimethane-sulphonyloxybutane, one of a series of sulphonic acid esters. The substance itself is an alkylating agent and therefore capable of producing improvement in lymphomas but its principal action is against the white cells of the granular series and this does direct its use as an important drug in chronic myeloid leukaemia. Galton $^{22}$ described the use of this substance in I9 cases of chronic myeloid leukaemia and demonstrated that it was possible to produce a remission in this disease which was in every way comparable to that obtained with high voltage irradiation to the spleen. One case of a remission lasting $2 \mathrm{I}$ months is cited. Many other authors since then have confirmed the value of this compound in chronic myeloid leukaemia. Its exact place in the treatment of this condition is difficult to assess but the summing up of Haut et al..$^{23}$ is a fair statement of the position. They suggest this agent is at least equal to $\mathrm{X}$-ray therapy to the spleen or radioactive phosphorus and is possibly superior to other chemotherapeutic agents; whilst Galton and Till ${ }^{24}$ consider that the chief use of myleran occurred when radiotherapy had been of limited value or had ceased to be effective. To this can be added the author's opinion that is reasonable to alternate myleran and high voltage $\mathrm{X}$-rays during successive periods of relapse.

Dose rate. $0.06 \mathrm{mg}$. per $\mathrm{kg}$. per day and if maintenance therapy is attempted $\frac{1}{4}$ to $4 \mathrm{mg}$. daily.

Side-effects. Thrombocytopenia, brownish pigmentation of the face, forearms, chest and abdomen.

Two derivatives of myleran have recently been mentioned in the literature-dimethyl myleran (Bierman et al. ${ }^{25}$ ) and nonane, Miller ${ }^{26}$ which was stated to have wide anti-tumour effect in transplanted animal tumours, but it is too early yet to assess efficacy of these compounds.

\section{Anti-Metabolites}

\section{Aminopterin}

Farber ${ }^{4}$ demonstrated it was possible to produce disease remissions in children with acute leukaemia by means of the folic acid antagonist, 4-aminopteroylglutamic acid (aminopterin). This observation has inspired a great deal of work into means of interfering and blocking the bio-synthetic pathways which lead to the synthesis of nucleic acid and nucleo proteins. This is sometimes called a rational approach to chemotherapy or combination chemotherapy. Intensive work into the search for new anti-metabolites has resulted in the finding of the valuable compound, 6-mercaptopurine, an anti-purine.

\section{Methotrexate (Amethopterin)}

It has been shown by much experimental work that the 4-aminoderivatives of folic acid such as amethopterin, prevent the conversion of PGA (Pteroylglutamic acid) into citrovorum factor. The precise site of action of these compounds has been shown to be the prevention of reduction of PGA to tetrahydro PGA Blakley. ${ }^{27}$

$A$ vast amount of experience has been accumulated particularly in the Children's Hospital at Boston and at the Memorial Centre in New York in the use of methotrexate in the treatment of acute leukaemias. American workers are agreed that the first line of attack in the acute leukaemias of children lies in the use of methotrexate. For some curious reason in the acute leukaemias of adults, methotrexate is far less efficacious than is 6-mercaptopurine. In children, however, Farber ${ }^{28}$ has shown what great strides have been made in the control of the acute leukaemias. He quotes 549 cases of which 50 per cent. survived nine months. This is to be compared with the median duration of acute untreated cases as quoted by Tivey ${ }^{29}$ who mentions one to two months. Farber ${ }^{28}$ also estimates that the average length of remission following methotrexate (eight months) is longer than average remission following 6-mercaptopurine (six months). No significant benefit has been reported in solid tumours and other lymphomas but in children, occasional good results have occurred in rhabdomyosarcomas, Hodgkin's disease and neuroblastomas.

Dosage. 2.5 to $7.5 \mathrm{mg}$. daily by mouth followed by maintenance therapy of 1.25 to $2.5 \mathrm{mg}$. per day.

Side-effects. Ulceration of buccal mucosa and gastro-intestinal tract, diarrhoea and intestinal bleeding. Bone marrow depression.

\section{6-Mercaptopurine (Purinethol)}

6-Mercaptopurine was first synthesized at the Wellcome Research Laboratories (Hitchings and Elion $^{30}$ ) following investigation into a series of chemical relatives of natural purine and pyrimidine bases. Its clinical use has been fully described by Burchenal et al. . $^{31}$ in trials on 269 patients with various neoplastic diseases. They decided that no beneficial effect followed its use in metastatic carcinomas, sarcomas, lymphosarcomas, Hodgkin's disease or chronic lymphatic leukaemia. It is capable of producing good clinical remission of disease with temporary return of the child to good health in acute leukaemia. They mention good clinical and haematological remissions in 41 out of 87 children but similar response in only 7 out of 50 in adults with the same disease. The place of mercaptopurine then lies principally in the treatment of acute leukaemias of childhood when it should be used, not as the initial treatment, but 
for the first relapse of disease following methotrexate therapy. It should be noted that it takes 4 to 13 weeks to attain satisfactory response to treatment with 6-mercaptopurine. It is therefore essential to continue treatment at full therapeutic levels for an adequate trial period: 6-Mercaptopurine apart from its capabilities in the chronic phase of the disease, has been reported as producing remission in two out of six cases of chronic myeloid leukaemia in the acute myloblastic phase and also has been successful in producing occasional remissions in generalized reticulum cell sarcoma (Hyman et al. . $^{2}$ ).

Dosage. $2.5 \mathrm{mg}$. per kg. per day by mouth for 4 to 13 weeks, followed by maintenance therapy of r.5 to $2.5 \mathrm{mg}$. per kg. per day.

Side-effects. Nausea, oral lesions, gastro-intestinal disturbance and bone marrow depression.

\section{Actinomycin ' D'}

Actinomycin ' $\mathrm{D}$ ' is an antibiotic which has been shown both experimentally and clinically to have important anti-tumour effects (Farber, ${ }^{33}$ Tan et al.$\left.^{34}\right)$. Both these groups of observers have evaluated the potentialities of this antibiotic principally in malignant disease of childhood. Tan mentioned definite objective response in four out of 12 cases of Wilm's tumours, three out of seven neuroblastomas and two out of three lymphomas. Farber also was impressed by the regression which had been brought about in Wilm's tumour. Both these authors have commented on the curious ability of actinomycin ' $D$ ' to potentiate radiotherapeutic effects.: For example, a patient previously treated by radiotherapy and subsequently given a course of actinomycin ' $\mathrm{D}$ ' is liable to a skin flare up in the previously irradiated areas. There can be no doubt that actinomycin ' $\mathrm{D}$ ' is an extremely interesting and potentially valuable substance which requires further investigation.

Dosage. Short-course therapy: $75 \mu \mathrm{g}$. per kg. daily intravenously for five days. Long-course therapy: $100 \mu \mathrm{g}$. a day given until signs of toxicity appear.

Side-effects. Oral ulceration, nausea, anorexia, vomiting, alopecia and occasional white blood cell and platelet depression.

\section{Urethane (Ethylcarbonate)}

Urethare (ethylcarbonate) came to the fore in r 946 when its potentialities in the treatment of chronic myeloid leukaemia was discovered (Paterson et $a^{35}$ ). It is not now much used except in the treatment of multiple myelomatosis although in the author's opinion it is not superior in this respect to nitrogen mustard or leukeran.
More recently sarcolysin has been reported by the Russians (Blokhin ${ }^{10}$ ) as being capable of bringing about a satisfactory clinical response in multiple myeloma.

Dosage. $\quad 1.5$ to $2.5 \mathrm{mg}$. per $\mathrm{kg}$. per day.

Side-effects. Anorexia, nausea, stomatitis $\overrightarrow{\vec{s}}$ vomiting and drowsiness.

\section{General Cell Poisons Colcemid}

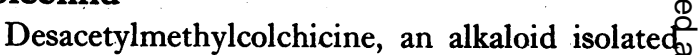
from colchicum autumnale, has a toxicity in ${ }^{\circ}$ animals $1 / 3$ oth that of colchicine itself. Moeschlin $\overrightarrow{0}$ et al.,$^{36}$ following initial experimental work in which it was demonstrated that colcemid had selectivelyo inhibited granulocytopoesis, treated patients witho chronic myeloid leukaemia. There was no doubt that a good remission could be obtained with thisis compound. Moeschlin mentions good improve $-\vec{t}$ ment in the general condition with increasingeto haemoglobin and diminution in white cell countos and size of spleen in 28 out of 30 patients with chronic myeloid leukaemia. In addition he main-윽 tains that maintenance therapy for as long as threeyears is perfectly safe provided the patient is kept? under observation. Furthermore, in the myloblastic transformation of chronic myelojis leukaemia, three out of five cases were said to hateed responded well. Myleran itself is probably nôt active in this stage of the disease. It is generaly agreed that colcemid is contra-indicated in chrowisico lymphatic leukaemia, because of the danger :of agranulocytosis $\left(\mathrm{Zbinden}^{37}\right)$. In 22 cases of carcinomas and sarcomas no definite therapeutico effect was observed in any case (Moeschlin ${ }^{36}$ ).

Dosage. $4 \mathrm{mg}$. daily gradually increasing up toळ $6 \mathrm{mg}$. daily after two to three weeks with a limit of 8 to Io $\mathrm{mg}$. daily. It is advisable to discontinue 3 treatment when the total white cell count has fallen to 30,000 . If maintenance therapy is: attempted, one-third of original daily dose is given.-

Side-effects. Loss of hair, rarely nausea and 3 . vomiting.

\section{Thiocolciran}

Desacetylthiocolchicine, a derivative of colcemid, has been developed in France. Huguenin et al. ${ }^{380}$ claimed that there was little effect on solid tumours $>$ but striking results were accomplished by a․ㅡ. combination of radiotherapy and thiocolciran. N The French claim that thiocolciran acts as a radio-r sensitizer is not supported by Levine. ${ }^{39}$ Heo mentions that when thiocolciran is administered intra-peritoneally to mice bearing five-day-oln tumour implants and these are subsequently givedo high voltage $\mathrm{X}$-rays, there is no significant increase in the number of mice showing complete tumour? regression as compared with controls. Neverthe $-\frac{0}{\bar{O}}$ 
less, thiocolciran is probably a useful agent in that it is not unduly toxic and there are no undesirable side-effects apart from occasional pain at tumour sites following intravenous injections. At Westminister Hospital, in two cases of epithelial cancer, namely, carcinoma of the stomach and lymphoepithelioma of the naso-pharynx, definite temporary disease control has been achieved with intravenous thiocolciran.

Dosage. $2 \mathrm{mg}$. daily rising to maximum of $20 \mathrm{mg}$. per day, then $20 \mathrm{mg}$. three times a week which may be continued as long as the blood count is satisfactory.

Side-effects. Pain at site of tumour. No nausea or vomiting observed. Bone marrow depression.

\section{Chemotherapy in Relation to Surgery}

It has been stated that chemotherapeutic substances such as ThioTEPA are capable of markedly reducing the number of artificial pulmonary metastases resulting from injecting melanoma cells in mice (Kramer et al. ${ }^{40}$ ). ThioTEPA has also proved successful in the prevention or diminution of the number of pulmonary metastases following removal of the primary malignant melanoma on the limbs of mice (W. Kramer and W. Schatten ${ }^{41}$ ). Animal work such as this has rationalized the administration of chemotherapeutic compounds during surgical removal of primary malignant disease. At Westminster Hospital it is now common to give intravenous nitrogen mustard, $\mathrm{HN}_{2}$, before, during and after an operation for excision of a primary malignant melanoma. There would seem to be reasonable grounds for giving similar courses of chemotherapy when other types of primary malignant tumours are removed.

\section{Summary}

Chemotherapeutic agents in present-day use have been classified and an account given of the more important agents together with indication for their use, dosage and side-effects.

\section{Acknowledgment}

I would like to take the opportunity of thanking Sir Stanford Cade who is largely responsible for initiating my interest in this subject.

\section{REFERENCES}

I. RHOADS, C. P. (1946), F. Amer. med. Ass., 131, 656.
2. GOODMAN, L S. WINTROBE, M. M., DAMESHEK, W. GOODMAN, M. J., GILMÁN, A., and MCLENNAN, M. T. (1946), F. Amer. med. Ass., 132, 126.

3. WILKINSON, J. F., and FLETCHER (1947), Lancet, ii, 540.

4. FARBER, S. DIAMOND, L. K., MERCER, R. D., SYLVESTER, R. F., Jr., and WÖLFF, J. A. (1948), New Engt. F. Med., 238; 787 .

5. EVERETT, I. L. ROBERTS, J. R., and ROSS, W. C. J. (1953), f. chem. Soc., 2386.

6. ALTMAN, S. J., HAUT, A., CARTWRIGHT, G. E., and WINTROBE, M. M. (1956), Cancer, 9, 512 .

7. GALTON, D. A. G., ISRAELS, L. G., NABARRO, J. D. N., and TILL, M. (1955), Brit. med. '尹F., ii, 1172 .

8. PILLERS, E. K., MAGALINI, S. I. (1958), Cancer, II, 410.

9. LARIONOV L. F SHKODINSKAJA, E. N. TROOSHEIKINA, V. I., KHHOKHLOV, A. S., VASINA, O. S., and NOVIKOVA, M. A. (1955), Lancet, ii, 169 .

Io. BLOKHIN, N., LARIONOV, L. F., PEREVODCHIKOVA, M., CHEBO'TAREVA, L., and MERKULOVA, N. (1958), Ann. N.Y. Acad. Sci., 68, 1128.

I. PAPAC, R., GALTON, D. A. G., TILL, M., and WILTSHAW, E. (1958), Ann. N.Y.'Acad. Sci., 68, 1 i 26.

12. HOLLAND, J. F., and REGELSON, W. (1958), Ann. N.Y. Acad. Sci., 68, 1122.

13. SELLEI, C., and ECKHARDT, S. (1958), Ann. N.Y. Acad. Sci., 68, 1164 .

14. ROSE, F. L., HENDRY, J. A., and WALPOLE, A. L. (1950), Nature, $165,993$.

15. BAYRD E. D., STICKNEY, I. M. HALL, B. E., and WATKINS, C. H. (1952), Cancer, 5, 336.

16. RUNDLES, R. W., and BARTON, W. B..(1952), Blood, 7, 483 .

17. SILVERBERG, J., and DAMESHEK (1952), f. Amer. med. Ass., 148, 1015.

I8. KRAVITZ, S. C., DIAMOND; H. D., and CRAVER, L. F. (1952), Blood, 7, 729.

19. BATEMAN, J. C., and MCCABE, M. (1955), F. Acta Unio Intern. Contra Canorum, II, III.

20. ULTMANN, J, HYMAN, G., CRANDALL, C., NAUJOKS H., and GELLHORN, A. (1957), Cancer, 10, 5, 902.

21. HADDOW, A., and TIMMIS, G. (1953), Lancet, i, 207

22. GALTON, D. A. G. (1953), Lancet, i, 208.

23. HAUT, A., ALTMAN, S. J., CARTWRIGHT, G. E., and WINTROBE, M. M. (1955), Arch. intern. Med., 96, $45 \mathrm{I}$.

24. GALTON, D. A. G., and TILL, M. (1955), Lancet, 1; 425. 25. BIERMAN, H. R.; KELLY, K. H., KNUDSON, A. G. Jr.,
MAEKAWA, T., and TIMMIS, G. M. (1958), Ann. N.Y' Acad. Sci., 68, $121 \mathrm{I}$.

26. MILLER, E. (1958), Ann. N.Y. Acad. Sci., 68, 1205.

27. BLAKLEY, R. L. (1954), Biochem. F., 58, 448 .

28. FARBER, S. (1957), The Leukaemias N.Y.; 623.

29. TIVEY, H. (1954), Ann. N.Y. Acad. Sci., 60, 322.

30. HITCHINGS, G. H., and ELION, G. B. (i954), Ann. N.Y. Acad. Sci., 60, 195.

31. BURCHENAL, J. H., ELLISON, R. R., MURPHY, M. L. KARNOFSKY, D. A., SYKES, M.'P., TAN, C. T. C., MERMANN, A. C. ' Y'UCEOGLU, M'., MYERS, w. 'P.' L.' KRAKOFF, I.', and ALBERSTÄDT, N.' (1954), Ann. N.Y. Acad. Sci., 60, 359.

32. HYMAN, G., GELLHORN, A., and WOLFF, J. (1954), Ann. N.Y. Acad. Sci., 60, 430 .

33. FARBER, $S$. (1958), 7th International Cancer Congress. Abstracts of Papers, p. 7 .

34. TAN, C. T. C., MURPHY, M. L., and BURCHENAL, J. H. (1958), 7th International Cancer Congress. Abstracts of Papers, p. 295.

35. PATERSON, E., HADDOW, A., THOMAS, J. A., and WATKINSÖN, J. M. (I946), Lancet, i, 677 .

36. MOESCHLIN, S., MEYER, H., and LIGHTMAN, A. (1954), in 'Ciba Foundation Symposium on Leukaemia Research', p. 216.

37. ZBINDEN, F. (1955), Schweiz. med. Wschr., 85, 994.

38. HUGUENIN, R., TRUHAUT, R., and SARACINO, $R$. (1955), Bull. 'Ass. franc. Cancer 42, 308 .

39. LEVINE, M. (1951), Ann. N.Y. Acad. Sci., 51, 1365.

40. KRAMER, W. M., ECK, R. V., and SMITH, R. R. (1958), Surg. Gynec. Obstet., 106, 427.

41. KRAMER, W. M., and SCHATTEN, W. E. (1958), Cancer, II, 463 . 